\title{
Control of epilepsy associated with cerebral arteriovenous malformations after radiosurgery
}

Hiroki Kurita, Shunsuke Kawamoto, Ichiro Suzuki, Tomio Sasaki, Masao Tago, Atsuro Terahara, Takaaki Kirino

\begin{abstract}
Objective-To investigate the effect of radiosurgery for symptomatic epilepsy associated with cerebral arteriovenous malformations (AVMs).

Methods- Thirty five patients with unruptured epileptogenic AVMs were studied with a mean follow up of 43.0 months. The duration of epilepsy before radiosurgery ranged from 2 months to 21 years (mean 2.8 years). Fifteen patients showed partial seizures; eight of these had associated secondary generalisation. The remaining 20 patients showed only generalised seizures without preceding focal seizures.

Results-At the final follow up examination, 28 patients remained seizure free, whereas seizures continued in seven. Variables significantly associated with continuity of seizures after radiosurgery were the number of seizures before therapy $(p<0.01)$ and duration of epilepsy $(p<0.05)$. According to Engel's classification, the 10 patients with intractable seizures before treatment included five with grade I, four with grade III, and one with grade IV. The frequency of seizures began to decrease several months after radiosurgery; much shorter than the time required for morphological change in the AVMs.
\end{abstract}

Table 1 Initial manifestations of 315 patients radiosurgically treated for $A V M$

Correspondence to:

Dr Hiroki Kurita,

Department of

Neurosurgery, Faculty of

Medicine, University of

Tokyo, 7-3-1, Hongo,

Bunkyo-ku, Tokyo 113-8655,

Japan. Telephone 00813

3815 5411; fax 008135800

8655 .

Received 16 October 1997

and in revised form

15 April 1998

Accepted 28 April 1998

\begin{tabular}{lrr}
\hline & \multicolumn{2}{l}{ Patients } \\
\cline { 2 - 3 } Symptoms & No & \multicolumn{1}{c}{$\%$} \\
\hline Haemorrhage & 228 & 72.4 \\
Seizure & 42 & 13.3 \\
Headache & 15 & 4.8 \\
Neurological deficits & 10 & 3.2 \\
Others & 3 & 1.0 \\
Incidental & 17 & 5.4 \\
Total & 315 & 100.0
\end{tabular}

Table 2 Location of arteriovenous malformations (AVMs) and type of seizures

\begin{tabular}{|c|c|c|c|c|c|c|}
\hline \multirow[b]{2}{*}{ Location of $A V M$} & \multirow[b]{2}{*}{ Patient No } & \multicolumn{2}{|c|}{ Side } & \multicolumn{3}{|c|}{ Type of seizures } \\
\hline & & $L$ & $R$ & SPS & CPS & $S G$ \\
\hline Frontal & 10 & 7 & 3 & 2 & 1 & $10\left(8^{\star}\right)$ \\
\hline Parietal & 7 & 5 & 2 & 3 & 1 & $3\left(3^{\star}\right)$ \\
\hline Temporal & 13 & 9 & 4 & 1 & 3 & $11\left(9^{\star}\right)$ \\
\hline Occipital & 5 & 1 & 4 & 5 & 0 & $4\left(0^{\star}\right)$ \\
\hline Total & 35 & 22 & 13 & 11 & 5 & $28\left(20^{\star}\right)$ \\
\hline
\end{tabular}

SPS=simple partial seizure; $\mathrm{CPS}=$ complex partial seizure; $\mathrm{SG}=$ secondarily generalised seizure. ${ }^{\star}$ Generalised seizure without aura or focal symptoms.
Conclusions-Radiosurgery seems to be beneficial for seizure control in patients with unruptured epileptogenic AVM.

(F Neurol Neurosurg Psychiatry 1998;65:648-655)

Keywords: arteriovenous malformation; symptomatic epilepsy; gamma knife; radiosurgery

Various therapeutic alternatives are currently available for eliminating the risk of bleeding from cerebral arteriovenous malformations (AVMs), and the reported treatment results have been favourable in terms of overall morbidity and mortality. However, the prognosis of epilepsy associated with cerebral AVMs has received little attention. Controversy exists on the surgical treatment of AVMs associated with epilepsy, and seizure outcome after AVM radiosurgery has not been documented in detail.

In this study, we analysed the characteristics and frequency of seizures in 35 patients with epileptogenic unruptured AVMs after gamma knife radiosurgery. A retrospective survey of 22 additional patients with unruptured nonepileptogenic AVMs was also done to assess the development of seizures after the procedure. Here we report the early effect of focused irradiation on seizures associated with AVMs and discuss the various factors that influence the prognosis.

\section{Patients and methods}

PATIENT POPULATION

Between June 1990 and December 1995, 315 patients with angiographically demonstrable cerebral arteriovenous malformations (AVMs) underwent radiosurgical treatment at our institution. The initial manifestation at diagnosis was haemorrhage in $228(72.4 \%)$, seizure in 42 $(13.3 \%)$, headache in $15(4.8 \%)$, progressive or stable neurological deficits in $10(3.2 \%)$, and other clinical symptoms in three $(1.0 \%)$. In the remaining 17 patients (5.4\%), AVM was an incidental finding (table 1 ).

From 42 patients who had epilepsy as a diagnostic symptom, we excluded five who underwent surgical resection or had a bleeding episode before radiosurgery, one whose AVM bled during the latent interval after radiosurgery, and one who had an infratentorial AVM. The present retrospective study was based on 35 patients with epileptogenic unruptured supratentorial AVMs with a clinical follow up of at least 18 months (mean 42.9 (SD 17.6) months).

There were 22 males and 13 females, aged between 12 and 50 years (mean 31.5 (SD 11.6) 
Table 3 Clinical summary of patients with epileptogenic/non-epileptogenic AVMs

\begin{tabular}{lll}
\hline Variable & $\begin{array}{c}\text { Patients with epileptogenic AVM } \\
(n=35)\end{array}$ & $\begin{array}{l}\text { Patients with non-epileptogenic } \\
\text { AVMs }(n=22)\end{array}$ \\
\hline Males/females & $22 / 13$ & $15 / 7$ \\
Age at radiosurgery & $31.5(11.6)(12-50)$ & $34.2(13.2)(13-56)$ \\
Mean nidus diameter $(\mathrm{mm})$ & $17.0(7.5)(0.6-36.0)$ & $19.5(5.6)(11.2-33.7)$ \\
Nidus volume $\left(\mathrm{cm}^{3}\right)$ & $3.9(4.3)(0.1-25.0)$ & $4.7(4.4)(0.7-20.0)$ \\
$\mathrm{R} / \mathrm{L}$ & $13 / 22$ & $17 / 5$ \\
Temporal/extratemporal lobe & $13 / 22$ & $7 / 15$ \\
Cortical/subcortical & $21 / 14$ & $9 / 13$ \\
Superficial/deep drainage & $27 / 8$ & $17 / 5$ \\
Duration of follow up & $43.0(20.0)(18-83)$ & $30.2(15.4)(12-62)$ \\
\hline
\end{tabular}

Figures in parentheses are (SD) (range).

years) at radiosurgery. The patients were aged 9 to 48 (mean 28.7 (SD 11.9 years) at seizure onset and had an average seizure history of 2.8 years (range 2 months to 21 years). Five patients had complex partial seizures, and 11 had simple partial seizures (focal motor in four cases, somatosensory in two, visual in five, and aphasic in two; two patients had two types of

Table 4 Seizure free rate according to clinical characteristics

\begin{tabular}{|c|c|c|c|c|}
\hline Characteristic & Seizure free rate & Statistic & $95 \% C I$ & $p$ Value \\
\hline \multicolumn{5}{|l|}{ Patient's characteristics } \\
\hline \multicolumn{5}{|l|}{ Age (y): } \\
\hline$\leqslant 34$ & $0.789(15 / 19)$ & 0.177 & $(-0.241$ to 0.289$)$ & NS \\
\hline$>34$ & $0.813(13 / 16)$ & & & \\
\hline \multicolumn{5}{|c|}{ 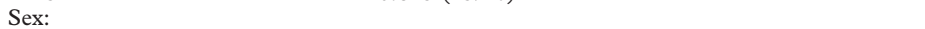 } \\
\hline Male & $0.864(19 / 22)$ & 1.229 & $(-0.116$ to 0.460$)$ & NS \\
\hline Female & $0.692(9 / 13)$ & & & \\
\hline \multicolumn{5}{|l|}{ Characteristics of seizure } \\
\hline \multicolumn{5}{|l|}{ Number of pretreatment seizures: } \\
\hline$\leqslant 5$ & $0.920(23 / 25)$ & 2.806 & (0.093 to 0.747$)$ & $<0.01$ \\
\hline$>5$ & $0.500(5 / 10)$ & & & \\
\hline \multicolumn{5}{|l|}{ Duration of seizure history } \\
\hline $\begin{array}{l}\text { (months): } \\
\leqslant 6\end{array}$ & $0.944(17 / 18)$ & 2.200 & $(0.046$ to 0.548$)$ & $<0.05$ \\
\hline$>0$ & $0.647(11 / 17)$ & 2.200 & $(0.04000 .540)$ & -0.05 \\
\hline \multicolumn{5}{|l|}{ Age at seizure onset $(\mathrm{y})$ : } \\
\hline$\leqslant 32$ & $0.789(15 / 19)$ & 0.177 & $(-0.241$ to 0.289$)$ & NS \\
\hline$>32$ & $0.813(13 / 16)$ & & & \\
\hline \multicolumn{5}{|l|}{ Seizure type: } \\
\hline $\begin{array}{l}\text { Partial seizure without } \\
\text { generalisation }\end{array}$ & $0.571(4 / 7)$ & 1.692 & $(-0.102$ to 0.674$)$ & NS \\
\hline Secondary generalised seizure & $0.857(24 / 28)$ & & & \\
\hline \multicolumn{5}{|l|}{ Characteristics of AVM } \\
\hline \multicolumn{5}{|l|}{ Side: } \\
\hline Right & $0.846(11 / 13)$ & 0.521 & $(-0.190$ to 0.336$)$ & NS \\
\hline Left & $0.773(17 / 22)$ & & & \\
\hline \multicolumn{5}{|l|}{ Location: } \\
\hline Temporal & $0.923(12 / 13)$ & 1.400 & $(-0.039$ to 0.431$)$ & NS \\
\hline Extratemporal & $0.727(16 / 22)$ & & & \\
\hline Cortical & $0.857(18 / 21)$ & 1.362 & $(-0.137$ to 0.423$)$ & NS \\
\hline Subcortical & $0.714(10 / 14)$ & & & \\
\hline \multicolumn{5}{|l|}{ Drainage: } \\
\hline Superficial & $0.875(7 / 8)$ & 0.602 & $(-0.711$ to 0.905$)$ & NS \\
\hline Deep & $0.778(21 / 27)$ & & & \\
\hline \multicolumn{5}{|l|}{ Nidus diameter $(\mathrm{mm})$ : } \\
\hline$\leqslant 18.1$ & $0.778(14 / 18)$ & 0.341 & $(-0.219$ to 0.311$)$ & NS \\
\hline$>18.1$ & $0.824(14 / 17)$ & & & \\
\hline \multicolumn{5}{|l|}{ Nidus volume $\left(\mathrm{cm}^{3}\right)$ : } \\
\hline$\leqslant 3.1$ & $0.778(14 / 18)$ & 0.341 & $(-0.219$ to 0.311$)$ & NS \\
\hline$>3.1$ & $0.824(14 / 17)$ & & & \\
\hline \multicolumn{5}{|l|}{ Treatment parameter } \\
\hline \multicolumn{5}{|l|}{ Central dose delivered (Gy): } \\
\hline$\leqslant 40$ & $0.880(22 / 25)$ & 0.839 & $(-0.195,0.455)$ & NS \\
\hline$>40$ & $0.750(6 / 8)$ & & & \\
\hline \multicolumn{5}{|l|}{ Marginal dose delivered (Gy): } \\
\hline$\leqslant 20$ & $0.769(20 / 26)$ & 0.774 & $(-0.141,0.381)$ & NS \\
\hline$>20$ & $0.889(8 / 9)$ & & & \\
\hline Follow up findings & & & & \\
\hline Angiographical cure: & & & & \\
\hline yes & $0.905(19 / 21)$ & 1.899 & $(-0.018,0.542)$ & NS \\
\hline no & $0.643(9 / 14)$ & & & \\
\hline Radiation-induced edema: & & & & \\
\hline yes & $0.750(9 / 12)$ & 0.535 & $(-0.214,0.366)$ & NS \\
\hline no & $0.826(19 / 23)$ & & & \\
\hline AED treatment at last follow up: & & & & \\
\hline yes & $0.750(18 / 24)$ & 1.089 & $(-0.084,0.402)$ & NS \\
\hline no & $0.909(10 / 11)$ & & & \\
\hline Length of follow-up (months): & & & & \\
\hline$\leqslant 36.0$ & $0.778(14 / 18)$ & 0.341 & $(-0.219,0.311)$ & NS \\
\hline$>36.0$ & $0.824(14 / 17)$ & & & \\
\hline
\end{tabular}

simple partial seizures, including one who had both simple and complex partial seizures. Eight patients with partial seizure had associated secondary generalisation. In 20 patients, only generalised seizures, which were presumably preceded by partial seizures, were noticed. At radiosurgery, all patients except one, who refused medication, were given antiepileptic drugs for seizure prophylaxis with a mean duration of 2.0 (SD 4.3) years. Patients were divided into two groups according to the number of seizures: few ( $\leqslant$ five and frequency $\leqslant 1 /$ month, 25 patients including 18 with single seizure) or numerous ( $>$ five and frequency $>1 /$ month, 10 patients).

Before irradiation, the AVMs were partially obliterated by transarterial embolisation in seven patients (total 16 procedures; mean 2.3 procedure/patient). Seizure frequency remained unchanged during the interval between embolisation and radiosurgery (mean 3.3 months, range 1 to 6 months). The patients were mentally and neurologically normal except for one with hemiparesis of the upper limbs due to polio and one with hemianopsia.

CHARACTERISTICS OF AVMS

In all cases, the AVM characteristics were defined by cerebral angiography. Most of the lesions in this series were small $(<3 \mathrm{~cm}$ in diameter). The diameter ranged from 0.6 to 36 $\mathrm{mm}$ (mean 17.0 (SD $7.5 \mathrm{~mm}$ )), and the volume from 0.1 to $25 \mathrm{~cm}^{3}$ (mean 3.9 (SD 4.3) $\mathrm{cm}^{3}$ ). In 21 patients $(60.0 \%)$, the AVMs were located in the cerebral cortex (cortical AVMs), and the other 14 in the white matter (subcortical AVMs). Seventeen AVMs (48.6\%) were located in the eloquent area of the brain, and eight $(22.8 \%)$ drained into deep veins. The most frequent location was the temporal lobe, followed by the frontal, parietal, and occipital lobes. The types of seizures and locations of the AVMs are summarised in table 2 .

To investigate the development of new seizures after radiosurgery, we also undertook a retrospective survey of 22 patients with AVMs with no history of seizures, haemorrhages, neurological deficits, or surgical resection treated in the same period (non-epileptogenic AVMs). There were no significant differences in the demographic characteristics of the patients between the epileptogenic and nonepileptogenic AVM groups (table 3).

\section{GAMMA KNIFE RADIOSURGERY}

Radiosurgery was performed using a 201 source ${ }^{60} \mathrm{Co}$ gamma unit. The definition of the nidus and localisation of the irradiation target were done on biplane stereotactic cerebral angiography. After April 1992, thin slice high resolution dynamic stereotactic CT was used in combination to obtain precise information on the three dimensional shape of the nidus. A MicroVAX computer system (Digital Equipment Corporation, Westminster, MA, USA) was used for complex dose planning. The radiation dose delivered to the margin of the nidus, and the number and configuration of irradiation isocentres were determined jointly by neurosurgeons and radiation oncologists. 
Table 5 Clinical summaries and responses to irradiation in 10 patients with numerous seizures before radiosurgery

\begin{tabular}{|c|c|c|c|c|c|c|c|c|c|}
\hline Patient & Age/sex & $\begin{array}{l}\text { Seizure } \\
\text { duration }\end{array}$ & Seizure type & Seizure frequency & Antiepileptic drug & $\begin{array}{l}\text { Volume of } \\
A V M\left(\mathrm{~cm}^{3}\right)\end{array}$ & $\begin{array}{l}\text { Location of } \\
A V M\end{array}$ & $\begin{array}{l}\text { Central/peripheral } \\
\text { dose }(G y)\end{array}$ & $A V M$ response \\
\hline 1 & $15 \mathrm{~F}$ & $5 y$ & $\begin{array}{l}\text { 1, SPS (m) 2, } \\
\text { SPS }(\mathrm{s})\end{array}$ & 1 , monthly 2 , monthly & PHT, PB & 25.0 & $\mathrm{R}$ parietal & $30 / 15$ & $\mathrm{NC}(6 \mathrm{y})$ \\
\hline 2 & $32 \mathrm{~F}$ & $11 \mathrm{y}$ & CPS, SG & Weekly & PHT, PB & 3.9 & $\mathrm{R}$ temporal & $40 / 20$ & CR (3 y) \\
\hline 3 & $26 \mathrm{M}$ & $1 \mathrm{y}$ & CPS & Weekly & CBZ, PHT,VPA & 5.5 & $\mathrm{R}$ temporal & $\begin{array}{l}\text { 1st: } 40 / 20 \star 2 \text { nd: } \\
40 / 20\end{array}$ & PR (3 y) CR (1.5 y) \\
\hline 4 & $14 \mathrm{~F}$ & $1.5 \mathrm{y}$ & $\begin{array}{l}\text { 1, CPS, } 2, \\
\text { SPS (m), SG }\end{array}$ & 1 , weekly 2 , monthly & CBZ, PB, VPA & 2.6 & L frontal & $40 / 20$ & PR (5 y) \\
\hline 5 & $34 \mathrm{~F}$ & $19 \mathrm{y}$ & SPS (v), SG & Monthly & PHT, PB & 3.3 & R occipital & $40 / 20$ & CR (3 y) \\
\hline 6 & $41 \mathrm{M}$ & $3 y$ & SPS (v) & †Daily & $\mathrm{CBZ}$ & 5.6 & R occipital & $40 / 20$ & $\mathrm{CR}(3 \mathrm{y})$ \\
\hline 7 & $43 \mathrm{~F}$ & $8 \mathrm{y}$ & SG & Monthly & PB & 1.1 & L temporal & $40 / 20$ & CR $(2.5 y)$ \\
\hline 8 & $44 \mathrm{~F}$ & $3.5 \mathrm{y}$ & SG & Monthly & VPA & 0.4 & L temporal & $40 / 20$ & PR $(2 y)$ \\
\hline 9 & $17 \mathrm{~F}$ & $0.5 \mathrm{y}$ & CPS & Weekly & ZNS & 0.6 & R parietal & $44.4 / 20$ & $\mathrm{PR}(1.5 \mathrm{y})$ \\
\hline 10 & $34 \mathrm{M}$ & $3.5 \mathrm{y}$ & SPS (s) & Monthly & refused & 6.9 & $\mathrm{R}$ parietal & $40 / 20$ & $\mathrm{CR}(1 \mathrm{y})$ \\
\hline
\end{tabular}

$\mathrm{NC}=$ no therapeutic response; $\mathrm{PR}=$ partial obliteration of the AVM; CR= total obliteration of the AVM; SPS=simple partial seizures: $(\mathrm{m})$; motor, $(\mathrm{s})$; somatosensory, (v); visual; $C P S=$ complex partial seizure; $S G=$ secondary generalized seizure; $P H T=$ phenytoin; $P B=$ phenobarbitone; $C B Z=$ carmabazepine; $V P A=$ valproate sodium; ZNS=zonisamide.

^ Small remnant of AVM was reirradiated 3 years after radiosurgery.

†Seizure frequency before introduction of CBZ, which was introduced 6 months before radiosurgery and discontinued 1 year later.

All patients continued to have antiepileptic drugs at radiosurgery. In patients who had multiple seizures before radiosurgery, phenobarbitone was administered intramuscularly immediately after the procedure.

FOLLOW UP EVALUATION

Clinical examinations and radiological check ups (MRI, or contrast CT, or both, and cerebral angiography in selected patients) were performed at 6 month intervals. In patients whose AVMs had disappeared on MRI or CT, cerebral angiography was performed. Most patients were maintained on the same dose of antiepileptic drugs after radiosurgery; slow drug withdrawal was then offered if they were seizure free for 2 years. For patients living away from our institution, radiological imaging, clinical examinations, and antiepileptic medication were provided by the referring neurosurgeons or neurologists and reviewed at our institute.

\section{TERMINOLOGY}

Patients were classed as "seizure free" if they had not experienced a seizure for at least 1 year at the final follow up examination, with or without antiepileptic medication. Seizures that occurred immediately after radiosurgery $(<24$ hours) were excluded from the analysis. Seizure outcome in patients with numerous seizures before radiosurgery was graded according to a simplified version of Engel's classification $^{1}$ (grade I: seizure free except for an occasional aura, grade II: rare seizures; 1-2/ year, grade III: worthwhile reduction in frequency or severity of seizures, grade IV: no worthwhile improvement).

STATISTICAL ANALYSIS

All data were presented as mean (SD). A test for proportion was used to identify clinical features associated with seizure control after irradiation. Continuous valuables were dichotomised at their median values. The MannWhitney rank test was used for non-parametric variables. The level of significance was $p<0.05$.

\section{Results}

SEIZURES IMMEDIATELY AFTER RADIOSURGERY Of 35 patients with a seizure history, four $(11.4 \%)$ had a seizure within 24 hours after radiosurgery, whereas the corresponding incidence was one of 22 patients $(4.5 \%)$ without a seizure history. In four of these five patients, the AVMs were located in the cerebral cortex. All of these patients remained seizure free subsequently, except for one who had an increased seizure frequency for several months after radiosurgery.

SEIZURE DEVELOPMENT AFTER RADIOSURGERY Of the 22 patients with no history of seizures, 21 did not experience seizure after radiosurgery within a mean follow up period of 33.5 months (range 12-62 months). One patient had seizures immediately after irradiation, but no recurrence was seen during follow up without medication. No patient developed late seizures after radiosurgery.

SEIZURE CONTROL AFTER RADIOSURGERY

Of the 35 patients with a seizure history before radiosurgery, $28(80 \%)$ were classed as "seizure free" at the last follow up examination. Of these patients, 10 were seizure free without receiving antiepileptic drugs, and four were in the process of tapering off. Another 14 patients continued the treatment regimen, including four in whom seizures had recurred 13-60 months after withdrawal of antiepileptic drugs. Among seven patients classed as "not seizure free" (at least one attack within the final year of follow up), seizure frequency was decreased in four and unchanged in two Only one patient had increased seizure frequency several months after radiosurgery. After radiosurgery, 34 patients received antiepileptic drugs with a mean duration of 2.9 (SD 1.6) years. At final follow up, 24 of 35 patients $(68.6 \%)$ continued receiving antiepileptic drugs; however, the medical status did not influence the seizure outcome.

On the other hand, the seizure free rate achieved $92 \%(23 / 25)$ in patients with few seizures before radiosurgery whereas the rate remained $50 \%(5 / 10)$ in patients with numerous seizures. The difference was significant $(p<0.01)$. Patients with a short history of 
Table 5 Continued

\begin{tabular}{|c|c|c|c|}
\hline $\begin{array}{l}\text { Brain } \\
\text { oedema }\end{array}$ & Change in seizure frequency & $\begin{array}{l}\text { Follow up } \\
\text { (months) }\end{array}$ & Seizure outcome (Engel grade) \\
\hline No & 1 , free since 8 months 2 , no change & 83 & Grade 3 AED continued \\
\hline No & $\begin{array}{l}\text { Decreased since } 4 \text { months free since } 37 \\
\text { months }\end{array}$ & 78 & Grade 1 AED discontinued \\
\hline No & $\begin{array}{l}\text { Decreased since } 3 \text { months free since } 41 \\
\text { months }\end{array}$ & 67 & Grade 1 AED reduced \\
\hline No & 1, no change 2 , free since radiosurgery & 70 & Grade 3 AED continued \\
\hline Local & $\begin{array}{l}\text { Decreased since } 4 \text { months free since } 35 \\
\text { months }\end{array}$ & 55 & Grade 1 AED continued \\
\hline Local & Free since radiosurgery & 48 & Grade 1 AED discontinued \\
\hline No & Free since radiosurgery & 32 & Grade 1 AED reduced \\
\hline No & No change & 24 & Grade 4 AED continued \\
\hline Local & Decreased since 3 months & 20 & Grade 3 AED continued \\
\hline Local & Decreased since 5 months & 18 & Grade 3 AED refused \\
\hline
\end{tabular}

seizures ( $\leqslant 6$ months) were also associated with significantly higher seizure free rate $(94.4 \%$; $17 / 18)$ than patients with a long seizure history $(64.7 \% ; 11 / 17) \quad(p<0.05)$. No other initial characteristics, treatment variable, or follow up findings influenced the seizure free rates. Variables examined and their significance are summarised in table 4.
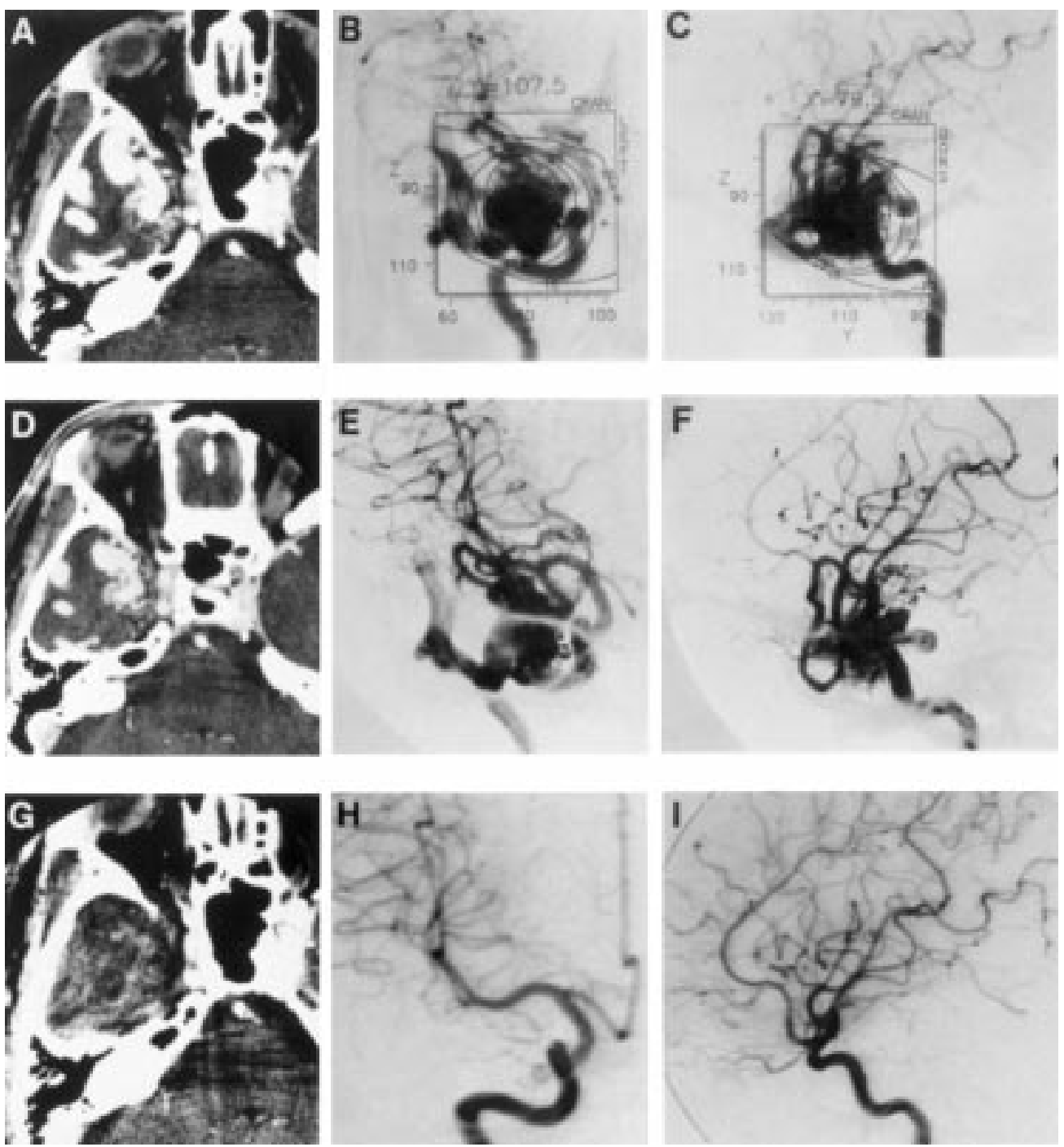

Figure 1 (A) Brain CT with contrast enhancement of patient 2 before radiosurgery, showing a right anteromedial temporal AVM with a maximum diameter of $2.5 \mathrm{~cm}$. (B) and $(C)$ Stereotactic right internal carotid angiography (ICAG); frontal and lateral projections showing the AVM. At radiosurgery, 20 Gy was delivered to the 50\% isodose line (maximum dose $40 G y$ ). (D) Contrast $C T ;(E)$ and $(F)$ right ICAG 1 year after radiosurgery, showing no morphological therapeutic response. (G) Contrast $C T$, and $(H)$ and (I) right ICAG 3 years after radiosurgery, showing total obliteration of the AVM. 

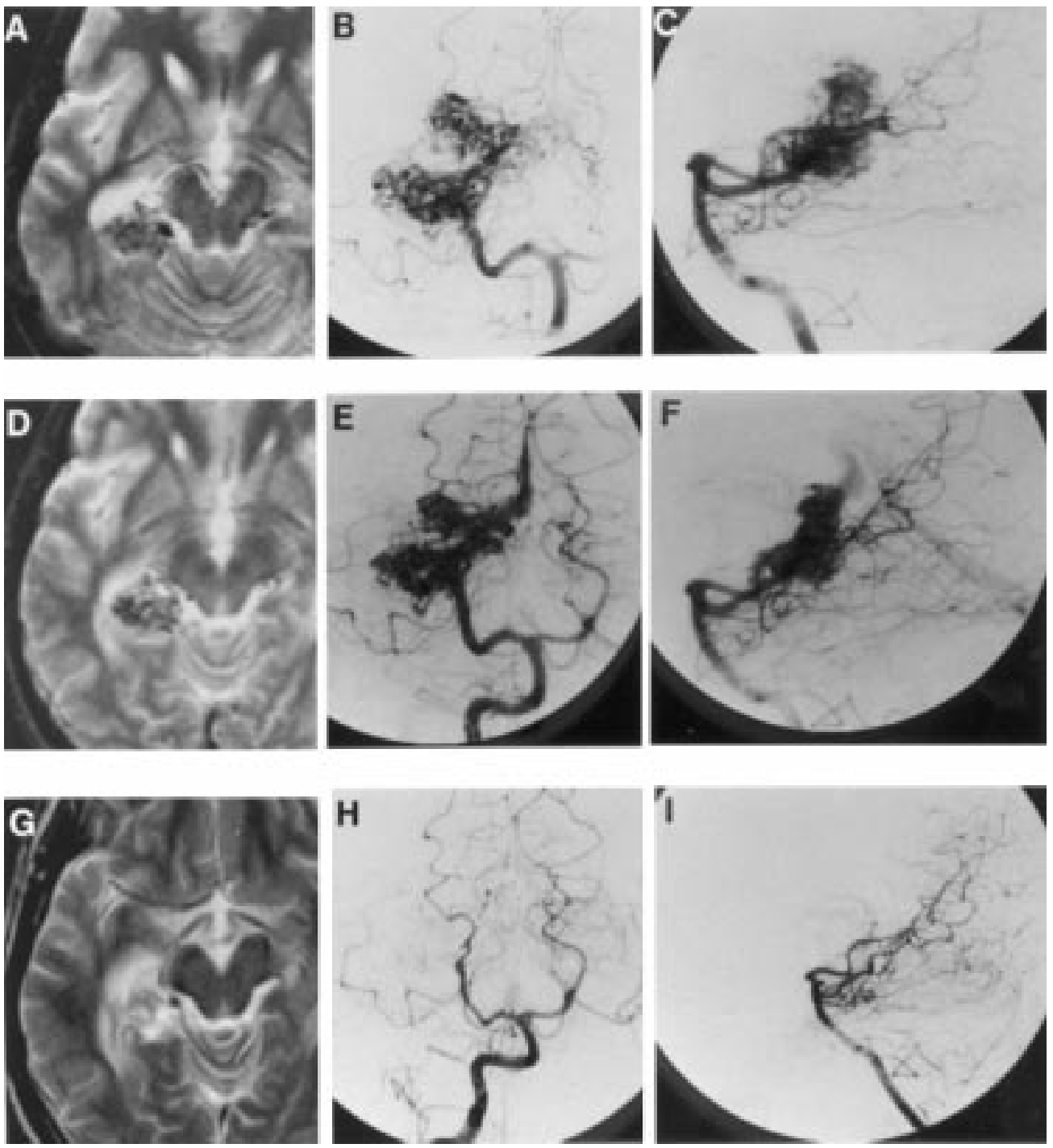

Figure 2 T2 weighted imaging of patient 3 before radiosurgery, demonstrating $(A)$ a right posteromedial temporal AVM with a maximum diameter of $2.5 \mathrm{~cm}$. (B) and (C) Right vertebral angiogram (VAG). Frontal and lateral projections before radiosurgery, showing the partially obliterated AVM after transarterial embolisation. A total of 20 Gy of irradiation was delivered to the periphery of the AVM at the first radiosurgical treatment. (D) T2 weighted MR image, and (E) and (F) right VAG 6 months after first radiosurgery, showing no morphological therapeutic response or adverse reactions to irradiation. Subsequently the patient underwent a second radiosurgery 2.5 years later to obliterate the small remnant of the AVM. (G) T2 weighted MR image, and $(H)$ and $(I)$ right VAG 1.5 years after second radiosurgery (4.5 years from first irradiation) confirming that the AVM was totally obliterated.

peared after radiosurgery, whereas the other type showed no change in frequency. Only one patient had seizures at the same frequency as that before radiosurgery.

Total obliteration of the AVM was confirmed in six patients (one of whom required further radiosurgery for residual AVM 3 years after initial irradiation), and five of them remained seizure free at the time of final evaluation. The AVMs were partially obliterated or showed no change in size in four patients, although seizure frequency was reduced with the exception of one. Asymptomatic radiation induced transient brain oedema was seen in four patients $(40 \%)$.

As a result, Engel grade I seizure outcome was attained in five patients, grade III in four, and grade IV in one. A positive effect of irradiation for seizure control was found in nine of 10 patients $(90 \%)$ with numerous symptomatic seizures associated with AVMs. The effect began to appear several months after irradiation, much earlier than, or even without, the morphological therapeutic response of the AVMs or any adverse effect on the surrounding brain tissue.

\section{ILLUSTRATIVE CASES}

\section{Patient 2}

This 32 year old woman had had an initial attack of generalised seizure at the age of 11 years. Despite antiepileptic medication, complex partial seizures developed subsequently. As she grew older, the frequency of complex partial seizures increased, reaching two to three times a week, occasionally associated with secondary generalisation. Before radiosurgery, an interictal scalp EEG showed sharp waves in the right temporal region. Brain CT with contrast medium showed a right anteromedial temporal AVM (fig 1 A). Cerebral angiography disclosed a high flow AVM fed mainly by the right anterior temporal artery, which drained into both 
the cortical and basal veins. Gamma knife radiosurgery was performed in December 1990. A total of 20 Gy of radiation were delivered in a single dose to the periphery of the nidus (fig $1 \mathrm{~B}, \mathrm{C}$ ). The seizures seemed unchanged for about 4 months after irradiation, and then decreased in frequency. At her 1 year follow up, CT and angiography showed no morphological therapeutic response (fig 1 $\mathrm{D}, \mathrm{E}, \mathrm{F})$. However, seizure frequency decreased to one every several months, and EEG showed a decrease of epileptic discharges. Total obliteration of the AVM was confirmed 36 months (fig $1 \mathrm{G}, \mathrm{H}, \mathrm{I}$ ) after radiosurgery, and the last seizure occurred 37 months after radiosurgery. After that time, she had been totally seizure free for 3 years with tapering off of antiepileptic drugs, and remained neurologically intact.

Patient 3

This 26 year old man had had a history of complex partial seizures for 1 year before diagnosis of AVM. The attacks recurred weekly despite antiepileptic medication. After partial obliteration of the nidus by transarterial embolisation in another hospital, he was transferred to our institution for radiosurgical treatment. Brain MRI showed a right posteromedial temporal AVM (fig 2 A). Cerebral angiography demonstrated a partially obliterated AVM fed mainly by the temporal branches of the posterior cerebral artery and lateral posterior choroidal artery, and drained into the Galenic system (fig 2 A,B,C). He underwent gamma knife radiosurgery in March 1991. The AVM was totally covered with more than 20 Gy. Seizure frequency decreased from 3 months after radiosurgery. At his 6 month follow up, seizure frequency had improved to one a month without any morphological response or an adverse effect of irradiation (fig $2 \mathrm{D}, \mathrm{E}, \mathrm{F}$ ). He experienced his last attack 41 months after irradiation. Subsequently, he underwent further radiosurgery for his small AVM remnant 3 years after initial radiosurgery, and total obliteration was confirmed 1.5 years later ( fig $2 \mathrm{G}, \mathrm{H}, \mathrm{I})$. Although he has continued to take a low dose of antiepileptic drugs, he has been totally seizure free for more than 2 years.

\section{Discussion}

EPILEPSY ASSOCIATED WITH AVM

Epilepsy is the second most common mode of presentation of cerebral AVMs. The reported incidence varies from $18 \%$ to $60 \% .^{2-11}$ However, compared with the numerous reports concerning the risk of bleeding, ${ }^{3812-15}$ the natural history of AVMs in relation to the risk of epilepsy and the factors influencing the epilepsy development remain less clear.

Several authors have suggested that seizures associated with AVMs are easy to control, ${ }^{57121617}$ and that surgery allows good control of epilepsy. ${ }^{5}$ 9 $^{17-21}$ Trumpy and Eldevik ${ }^{17}$ cured $50 \%$ of patients with preoperative seizures due to AVMs. Guidetti and Delitala ${ }^{18}$ reported that seizures were improved in $53 \%$ of patients after AVM surgery. Heros et $a \bar{l}$ reported that over half of all preoperative seizures were cured or greatly improved after resection of AVMs, and that only $12.7 \%$ worsened. In a recent report by Piepgras et al, the seizure free ratio after surgery was as high as $83 \%$ in patients with preoperative seizures and $94 \%$ in patients without. Several authors have recommended more radical resection including cortical excision of the epileptogenic foci around the AVMs. ${ }^{19-21}$

However, several studies disclosed that epileptogenic foci secondary to AVMs become progressively more intractable, ${ }^{22} 23$ or that surgery cannot contribute to seizure control. $^{27162425}$ Forster et $a l^{25}$ reported that only $4 \%$ of patients with epileptogenic AVMs were seizure free after surgery. Parkinson and Bachers ${ }^{16}$ stated that patients with preoperative seizures were likely to have them postoperatively. Drake ${ }^{26}$ concluded that excision of an AVM alone would not relieve associated epilepsy. The reported risk of new epilepsy after AVM surgery also varies, ranging from $<10 \%$ to $>50 \% .^{571216172425}$

SEIZURE OUTCOME IN PATIENTS WITH

RADIOSURGICALLY TREATED AVMs

Although the primary aim of radiosurgery for cerebral AVMs is to obliterate the nidus and eliminate the risk of bleeding, a positive effect of radiosurgery for seizure control has also been reported by several gamma knife users. ${ }^{27-31}$ Steiner et a $l^{29}$ reported that $69 \%$ of 59 patients with seizures became seizure free or were significantly improved after radiosurgery. In their series, 11 patients with medically intractable seizures became seizure free with or even without AVM obliteration. Lunsford et al ${ }^{28}$ noted that $51 \%$ of 43 patients showed improved seizure control, and only one showed deterioration. At the Mayo Clinic, ${ }^{27} 3120 \%$ of 59 patients with a seizure history showed a seizure decrease or elimination at the last follow up. Sutcliffe et $a l^{30}$ reported that $38 \%$ of 49 patients with seizures had no further seizures after radiosurgery, $22 \%$ improved, and $6 \%$ showed deteriorated seizure control. Similar effects of radiosurgery have been reported for different types of penetrating radiation, including protons, ${ }^{42}$ heavy charged particles, ${ }^{33} 34$ and $x$ irradiation..$^{35}$ On the contrary, Colombo et $a l^{36}$ stated that there was no significant influence of $x$ ray irradiation on seizure frequency or symptoms. Seifert et $a l^{37}$ reported an increase in seizure frequency in seven of 39 patients after proton beam irradiation.

These reports suggest that focused single high dose irradiation does have some beneficial effects on seizures related to AVMs in a proportion of cases. However, the frequency and severity of seizures before irradiation or course of seizure improvement after radiosurgery have not been well documented. Furthermore, the effect of irradiation has not been quantified because of the complexity of the variables affecting seizure control, such as medication, presence or absence of previous haemorrhage or surgery, and psychological factors. 
ANALYSIS OF THE PRESENT SERIES

In this series, four of 35 patients $(11.4 \%)$ with epileptogenic AVM, and one of 22 patients $(4.5 \%)$ with non-epileptogenic AVM had a seizure within 24 hours after irradiation. This so-called immediate epilepsy has been noted by several authors ${ }^{27} 283038$ as an acute morbidity of radiosurgery. However, this acute exacerbation effect of irradiation on seizure activity seems to be transient in most cases, and, with a few exceptions, does not affect long term seizure control. ${ }^{30}$ In fact, all of our patients with immediate epilepsy attained good seizure control afterwards, and none of 22 patients without seizures developed late seizures after radiosurgery within a mean follow up period of 33.5 months. Although this incidence compared favourably with reported surgical series, more long term follow up is necessary to determine whether radiosurgery has a protective effect against future development of epilepsy. On the other hand, $80 \%$ of 35 patients with epileptogenic AVMs remained seizure free, and epilepsy improved or disappeared in nine of 10 patients who had numerous seizures before radiosurgery. It must be plainly stated that there are no adequate controls in the present study, and the observation period for judging seizure control in not long enough to make definite conclusions. However, our experience suggests that radiosurgery allows seizure control in a proportion of treated patients with epileptogenic AVMs.

Analysis of factors affecting seizure control showed that a longer history and increased number of seizures were associated with a worse seizure outcome. Comparable findings have also been reported for AVM surgery. ${ }^{9021}$ In such cases, epileptogenic foci occurring at a distance from the AVM should be considered. . $^{39} 40$

On the other hand, the patients with angiographical obliteration tended to be associated with higher seizure free rate than non-obliterators $(90.5 \%$ v $64.3 \%)$. Indeed, ischaemia of the surrounding brain is considered to be one of the pathophysiological factors of epilepsy, and amelioration of the arteriovenous shunt should be expected to alter regional blood flow resulting in relief of epilepsy.

The mechanism of seizure control in the present series remains unresolved; however, our findings may provide some basis for considering the efficacy of irradiation on epileptic activity in the surrounding gliotic brain. ${ }^{41}$ Because the frequency of seizures began to decrease several months after irradiation, much earlier than, or even in the absence of morphological change in the AVMs. Similar putative therapeutic efficacy of irradiation has been seen in patients with tumour related epilepsy. ${ }^{42-47}$ Although there is only a small amount of solid evidence, irradiation of the epileptogenic focus has been reported to have a curative effect in selected series. ${ }^{48-51}$ The dose delivered to the foci has varied, the seizures began to improve after a period of between several months and one year, similar to our findings.
In conclusion, a single standard radiosurgical dose of irradiation can improve symptomatic epilepsy associated with AVMs in a proportion of treated patients. Our present findings should contribute to decision making when treating patients with epileptogenic unruptured AVMs.

This work was supported in part by a grant in aid for scientific research from the Ministry of Education, Science and Culture of Japan, a grant in Japan, a grant in aid for cancer research from the Ministry of for Research and Development of Nuclear Technology in Medifor Rese.

1 Engel J Jr. Outcome with respect to epileptic seizures. In: Engel J Jr, ed. Surgical treatment of the epilepsies. New York: Raven Press, 1987:553-71.

2 Crawford PM, West CR, Chadwick DW, et al. Arteriovenous malformations of the brain: natural history in unoperated malformations of the brain: natural history in unopert

patients. F Neurol Neurosurg Psychiatry 1986;49:1-10.
3 Fults D, Kelly DL Jr. Natural history of arteriovenous malformations of the brain. A clinical study. Neurosurgery 1984;15:658-62

4 Heikkinen ER, Konnov B, Melnikov L, et al. Relief of epilepsy by radiosurgery of cerebral arteriovenous malformations. Stereotact Funct Neurosurg 1989;53:157-66.

5 Heros RC, Korosue K, Diebold PM. Surgical excision of cerebral arteriovenous malformations: late results. Neurosurgery 1990;26:570-8.

6 Leblanc R, Feindel W, Ethier R. Epilepsy from cerebral arteriovenous malformations. Can $\mathcal{F}$ Neurol Sci 1983;10: $91-5$.

7 Murphy MJ. Long-term follow-up of seizures associated with cerebral arteriovenous malformations. Results of therapy. Arch Neurol 1985;42:477-9.

8 Ondra SL, Troupp H, George ED, et al. The natural history of symptomatic arteriovenous malformations of the brain: a 24-year follow-up assessment. $\mathcal{f}$ Neurosurg 1990;73:38724-year.

9 Piepgras DG, Sundt TM Jr, Ragoowansi AT, et al. Seizure outcome in patients with surgically treated cerebral arteriovenous malformations. F Neurosurg 1993;78:5-11.

0 Pool JL. Treatment of arteriovenous malformations of the cerebral hemispheres. $\mathcal{F}$ Neurosurg 1962;16:136-41.

11 Turjman F, Massoud TF, Sayre JW, et al. Epilepsy associated with cerebral arteriovenous malformations: a multivariate analysis of angioarchitectual characteristics. AfNR Am f Neuroradiol 1995;16:345-50.

12 Brown RD Jr, Wiebers DO, Forbes G, et al. The natural history of unruptured intracranial arteriovenous malformations. F Neurosurg 1988;68:352-7.

13 Graf CJ, Perret GE, Torner JC. Bleeding from cerebral arteriovenous malformations as part of their natural history. $f$ Neurosurg 1983;58:331-7.

14 Michelsen WJ. Natural history and pathophysiology of arteriovenous malformations. Clin Neurosurg 1979;26:307-13.

5 Wilkins RH. Natural history of intracranial arteriovenous malformations. A review. Neurosurgery 1985;16:421-30.

16 Parkinson D, Bachers G. Arteriovenous malformations. Summary of 100 consecutive supratentrial cases. $\mathscr{f}$ Neurosurg 1980;53:285-99.

17 Trumpy JH, Eldevik P. Intracranial arteriovenous malformations: conservative or surgical treatment? Surg Neurol 1977;8:171-5.

18 Guidetti B, Delitala A. Intracranial arteriovenous malformations: conservative and surgical treatment. $\mathcal{f} \mathrm{Neu}$ rosurg 1980;53:149-52.

19 Rasmussen T. Surgery of epilepsy associated with brain tumors. In: Purpura DP, Perry JK, Walker RD, et al, eds. Advances in neurology. Vol 8. Neurosurgical management of epilepsies. New York: Raven Press, 1975:227-9.

20 Yeh HS, Kashiwagi S, Tew JM Jr, et al. Surgical management of epilepsy associated with cerebral arteriovenous malformations. F Neurosurg 1990;72:216-23.

21 Yeh HS, Tew JM Jr, Gartner M. Seizure control after surgery on cerebral arteriovenous malformations. F Neurosurgery on cerebral $1993 ; 78: 12-8$.

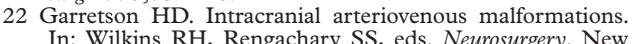
In: Wilkins RH, Rengachary SS, eds.
York: McGraw-Hill, 1985:1448-58.

23 Okabe T, Meyer JS, Okayasu H, et al. Xenon-enhanced CT $\mathrm{CBF}$ measurements in cerebral AVM's before and after excision: contribution to pathogenesis and treatment. $\mathcal{F}$ Neurosurg 1983;59:21-31.

24 Crawford PM, West CR, Shaw MD, et al. Cerebral arteriovenous malformations and epilepsy: factors in the development of epilepsy. Epilepsia 1986;27:270-5.

25 Forster DMC, Steiner L, Hàkanson S. Arteriovenous malformations of the brain. A long-term clinical study. $f$ Neurosurg 1972;37:562-70.

26 Drake CG. Cerebral arteriovenous malformations: considerations for and experience with surgical treatment in 166 cases. Clin Neurosurg 1979;26:145-208.

27 Coffey RJ, Nichols DA, Shaw EG. Stereotactic radiosurgical treatment of cerebral arteriovenous malformations. Mayo Clin Proc 1995;70:214-22.

28 Lunsford LD, Kondziolka D, Flickinger JC, et al. Stereotactic radiosurgery for arteriovenous malformations of the brain. F Neurosurg 1991;75:512-24. 
29 Steiner L, Lindquist C, Adler J, et al. Clinical outcome of radiosurgery for cerebral arteriovenous malformations. $\mathcal{F}$ radiosurgery for cerebral
Neurosurg 1992;77:1-8.

30 Sutcliffe JC, Forster DMC, Walton L, et al. Untoward clinical effects after radiosurgery for intracranial arteriovenous malformations. Br F Neurosurg 1992;6:177-85.

31 Yamamoto Y, Coffey RJ, Nichols DA, et al. Interim report on the radiosurgical treatment of cerebral arteriovenous malformations. The influence of size, dose, time, and technical factors on obliteration rate. $\mathcal{F}$ Neurosurg 1995;83:8327.

32 Kjellberg RN, Hanamura $\mathrm{T}$, Davis $\mathrm{KR}$, et al. Bragg-peak proton-beam therapy for arteriovenous

33 Levy RP, Fabrikant JI, Frankel KA, et al. Stereotactic heavycharged-particle Bragg peak radiosurgery for the treatment of intracranial arteriovenous malformations in childhood and adolescence. Neurosurgery 1989;24:841-52.

34 Steinberg GK, Fabrikant JI, Marks MP, et al. Stereotactic heavy-charged-particle Bragg-peak radiation for intracraheavy-charged-particle Bragg-peak radiation for intracra96-101.

35 Betti O, Munari C, Rosler R. Stereotactic radiosurgery with the linear accelerator treatment of arteriovenous malformations. Neurosurgery 1989;24:311-21.

36 Colombo F, Benedetti A, Pozza F, et al. Linear accelerator radiosurgery of cerebral arteriovenous malformations. Neurosurgery 1989;24:833-9.

37 Seifert V, Stolke D, Mehdorn HM, et al. Clinical and radiological evaluation of long-term results of stereotactic proton beam radiosurgery in patients with cerebral arteriovenous malformations. $\mathcal{F}$ Neurosurg 1994;81:683-9.

38 Friedman WA, Bova FJ, Mendenhall WM. Linear accelerator radiosurgery for arteriovenous malformations: the relationship of size to outcome. $\mathcal{F}$ Neurosurg 1995;82:180-9.

39 Morrell F. Secondary epileptogenesis in man. Arch Neurol 1985;42:318-35.

40 Yeh HS, Privitera MD. Secondary epileptogenesis in cerebral arteriovenous malformations. Arch Neurol 1991; 48: $1122-4$.
41 McCormick WF. Pathology of the vascular malformations of the brain. In: Wilson CB, et al, eds. Intracranial arteriovenous malformations. Baltimore: Williams and Wilkins, 1984:44-63.

42 Goldring S, Rich KM, Picker S. Experience with gliomas in patients presenting with a chronic seizure disorder. Clin Neurosurg 1986;33:15-42.

43 Rogers LR, Morris HH, Lupica K. Effect of cranial irradiation on seizure frequency in adults with low-grade astrocytoma and medically intractable epilepsy. Neurology 1993; 43:1599-601.

44 Spencer DD, Spencer SS, Mattson RH, et al. Intracerebral masses in patients with intractable partial epilepsy. Neurology 1984;34:432-6.

45 Alexander III E, Lindquist C. Special indications: radiosurgery for functional neurosurgery and epilepsy. In: Alexander III E et al, eds. Stereotactic radiosurgery. New York: McGraw-Hill, 1993:221-5.

46 Lance JW, Smee RI. Partial seizures with visual disturbance treated by radiotherapy of cavernous hemangioma. Ann Neurol 1989;26:782-5.

47 Rossi GF, Scerrati M, Roselli R. Epileptogenic cerebral lowgrade tumors effect of interstitial stereotactic irradiation on seizures. Appl Neurophysiol 1985;48:127-32.

48 Barcia-Salorio JL, Roldan P, Hernandez G, et al. Radiosurgical treatment of epilepsy. Appl Neurophysiol 1985;48:4003.

49 Barcia JA, Barcia-Salorio JL, Lopez-Gomez L, et al. Stereotactic radiosurgery may be effective in the treatment of idiopathic epilepsy: report on the methods and results of 11 cases. Stereotact Funct Neurosurg 1994;63:271-9.

50 Barcia-Salorio JL, Barcia JA, Hernandez G, et al. Radiosurgery of epilepsy. Long term results. Acta Neurochir (Wien) 1994; (suppl 62):111-3.

51 Heikkinen ER, Heikkinen MI, Sotaniemi K. Stereotactic radiotherapy instead of conventional epilepsy surgery. A case report. Acta Neurochir (Wien) 1992;119:159-60. 